\title{
An Experimental Study on Behaviour of Bamboo Reinforced Brick Aggregate Concrete Beam
}

\author{
Ranendra Nath Bhowmik ${ }^{\# 1}$, Joyanta Pal ${ }^{\# 2}$, Partha Pratim Sarkar ${ }^{\# 3}$ \\ ${ }^{\# 1}$ Ex-Post graduate student, Department of Civil Engineering, National Institute of Technology, Agartala, \\ Tripura, India \\ \#2\&\#3 Assistant Professor, Department of Civil Engineering, National Institute of Technology, Agartala, Tripura, \\ India \\ ${ }^{\# 1}$ ranen240892@gmail.com, ${ }^{\# 2}$ joyantanita@yahoo.com, ${ }^{\# 3}$ ps_partha@yahoo.com
}

\begin{abstract}
Bamboo is a giant grass which generally grows in the tropical and subtropical region around the world. The tensile strength of bamboo which is found to be significantly high makes it suitable to be used as reinforcing material with concrete. It is termed as bamboo reinforced concrete (BRC). In some parts of the world stone aggregate is poorly available and crushed brick is widely used as coarse aggregate in concrete which is termed as brick aggregate concrete (BAC). In the North eastern part of India especially in Tripura the availability of bamboo is enormous and brick aggregate concrete is very widely used. So, in this study an attempt has been made to utilize splint of Bambusa Balcooa species as reinforcing material in the brick aggregate concrete for making concrete beam. Beams using different percentage of bamboo reinforcement were prepared and test procedures were followed to evaluate ultimate load carrying capacity of bamboo reinforced beam. The average tensile strength of bamboo has been found as $287.69 \mathrm{MPa}$ in this study. The ultimate load carrying capacity has found to be increased by 4.88 times in case of bamboo reinforced beam. Experimental results proved bamboo as worthy material to be used as a reinforcing material in concrete elements.
\end{abstract}

Key words: Bamboo, Bambusa Balcooa , Bamboo reinforced concrete (BRC), Brick aggregate concrete (BAC), Tensile strength.

\section{INTRODUCTION}

Concrete is the most widely used construction material in the world. Concrete is good in compression but it behaves poorly when it is subjected to tensile forces. To overcome this shortcoming of concrete, reinforcement is required. The reinforcing material should have sufficient tensile strength apart from other properties. Steel is the conventional material used as reinforcement in concrete. It is available and affordable in most of the developed countries but unfortunately not in all parts of the world. If used so rapidly as current rate, at some point of time there may be scarcity of this material. So, it is important to think about new construction materials. Bamboo has a long and well established tradition as a building material throughout the world's tropical and sub-tropical regions. It is widely used for many forms of construction, in particular for housing in rural areas. Bamboo is a renewable and versatile resource. One of the properties that would make bamboo a good substitute to steel in reinforced concrete is its strength. Bamboo is very light in weight compared to steel. These aspects put bamboo on the list of viable construction materials. These properties, when combined, suggest that bamboo will make a fine addition to the current selection of materials.

From the past studies it has been observed that several attempts have already been made by researchers to make structural components like beam, column and slab using bamboo reinforcement. The durability was the main question mark regarding bamboo reinforced structures. But over the time researcher developed some technique to make the bamboo structure durable and serviceable. In north eastern part of India many bamboo species grows. The behaviour of these bamboos with concrete was not studied yet.

In the North-eastern part of India and in Bangladesh where there is a scarcity of natural stone aggregates, burnt clay bricks are used as a potential source of coarse aggregate and performance of concrete made with broken brick as coarse aggregate has been found quite extensive and satisfactory. concrete.

So, in this study an attempt has been made to study the behavior of bamboo reinforced brick aggregate 


\section{METHODOLOGY}

To prepare bamboo reinforced elements, various steps has been followed. Firstly, bamboo samples were seasoned to resist biological degradation and insect attack. Thereafter resistance coating has been provided to improve the bond between bamboo and concrete. After preparing concrete samples and proper curing, different test methods have been followed in the present study. The processes are described below.

\section{A. Seasoning and preparation of bamboo reinforcement bars}

Bamboo is a vegetable product and vulnerable to biological decomposition and insect attack. To make the bamboo a long lasting product a bamboo sticks were kept into a underground tank filled with pesticide solution for 15 days curing. Then the bamboo sticks were washed thoroughly to remove the harmful chemical from the surface and allowed to dry in sunlight for 4 days. Then the sticks were kept in upright position in a dry room for 2 weeks. Bamboo absorbs water and swells in soaking into water and also shrinks when dried. This property of bamboo causes poor bonding between concrete and bamboo. When embedded in concrete swelling of bamboo creates internal stress which can lead to cracking of concrete. To make bamboo bar water resistant SIKA HIBOND epoxy mix was applied on the bamboo surface thoroughly with a painting brush. Then the bamboo bars were kept in a dry room for 1days and the epoxy paint was allowed to harden. Then again the bamboo bars were painted with the epoxy and a thin layer of sand is applied on the newly painted bamboo bars. Then the bars were kept in a dry room for 3 days. Now the reinforced Bars were ready for binding.

\section{B. Tensile Strength of Bamboo}

The tensile strength of bamboo is the property which makes it good material to be used as reinforcement in concrete. The average tensile strength of the bambusa balcooa found to be $287.69 \mathrm{MPa}$. Tensile test samples of bamboo specimens were sized according to the Figure 1. The gauge length was narrowed so that grip failure could be avoided. The width throughout the gauge length was kept less than one third of the rest portion. The tensile strength test was done by a UNIVERSAL TESTING MACHINE equipped with LVDT. Figure 2 show that the stress -strain curve of bamboo samples resembles that of steel. However strength parameter is lesser than that of steel. Elasticity of bamboo recorded to be $43064.28 \mathrm{MPa}$ in this study.

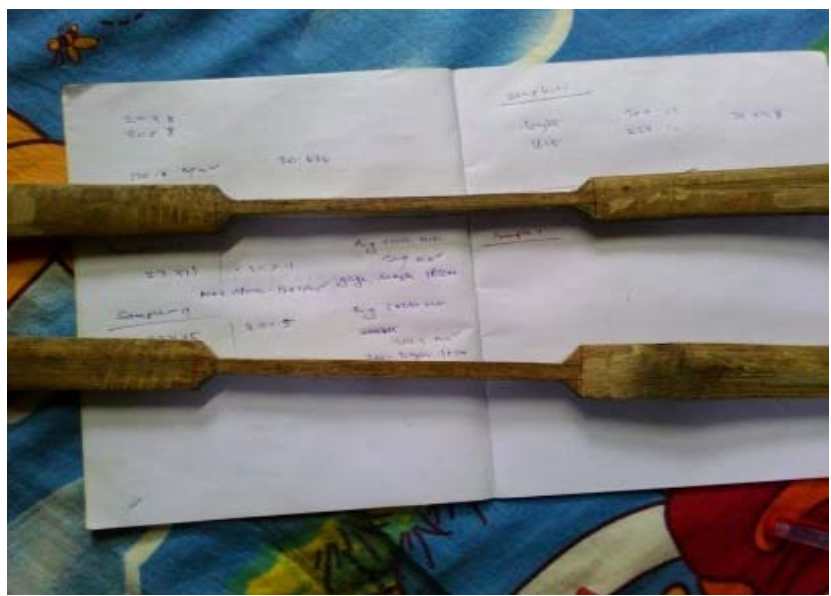

Fig.1. Tensile test samples of bamboo specimens. 


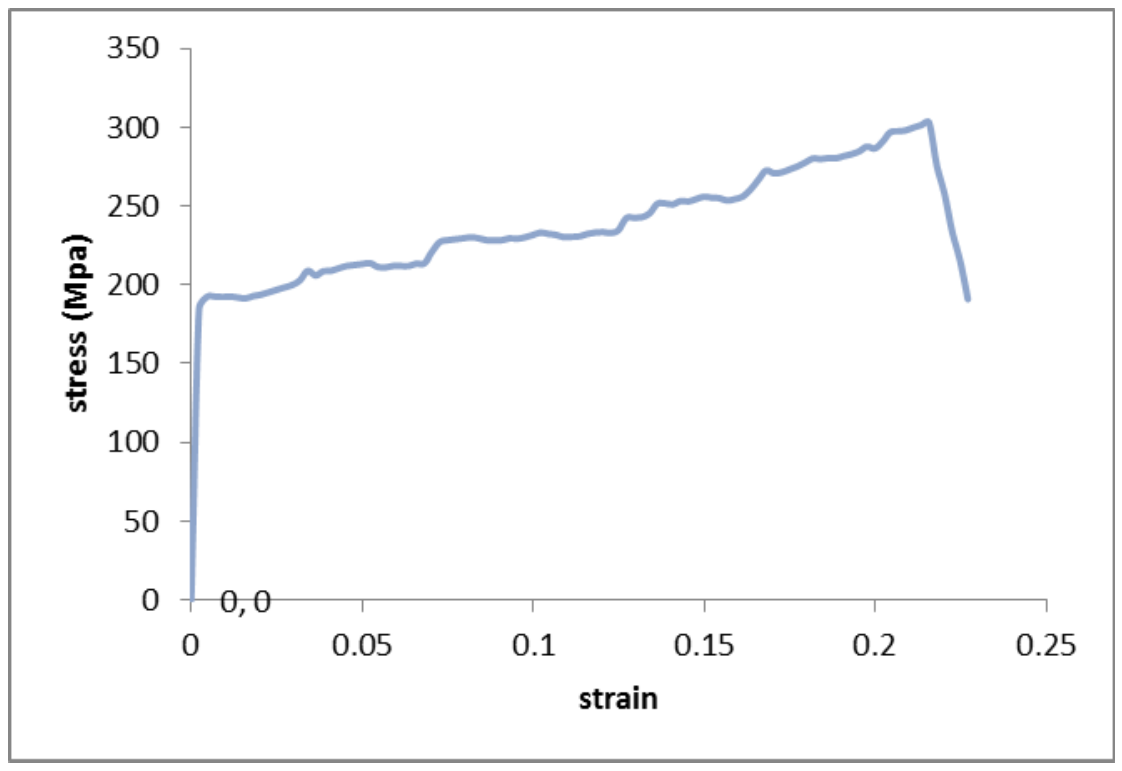

Fig. 2. Stress strain curve of bamboo splints

\section{Water Absorption Characteristics of Bamboo}

Bamboo absorbs water and swells after soaking into water and shrinks after being dried. This property of bamboo causes poor bonding between concrete and bamboo. When embedded in concrete swelling of bamboo generates internal stress which can lead to cracking of concrete. Water absorption of Bambusa Balcooa was found $25.45 \%$ and $45.19 \%$ after 24 hours and after 5 days respectively as shown in figure 3 . To make bamboo bar water resistant SIKA HIBOND epoxy mix was applied on the bamboo surface thoroughly with a painting brush. Then the bamboo bars were kept in a dry room for 1days and the epoxy paint was allowed to harden. Then again the bamboo bars were painted with the epoxy and a thin layer of sand was applied on the newly painted bamboo bars. Then the bars were kept in a dry room for 3 days. The use of sika-hibond epoxy layer reduces the water absorption capacity of bamboo significantly.

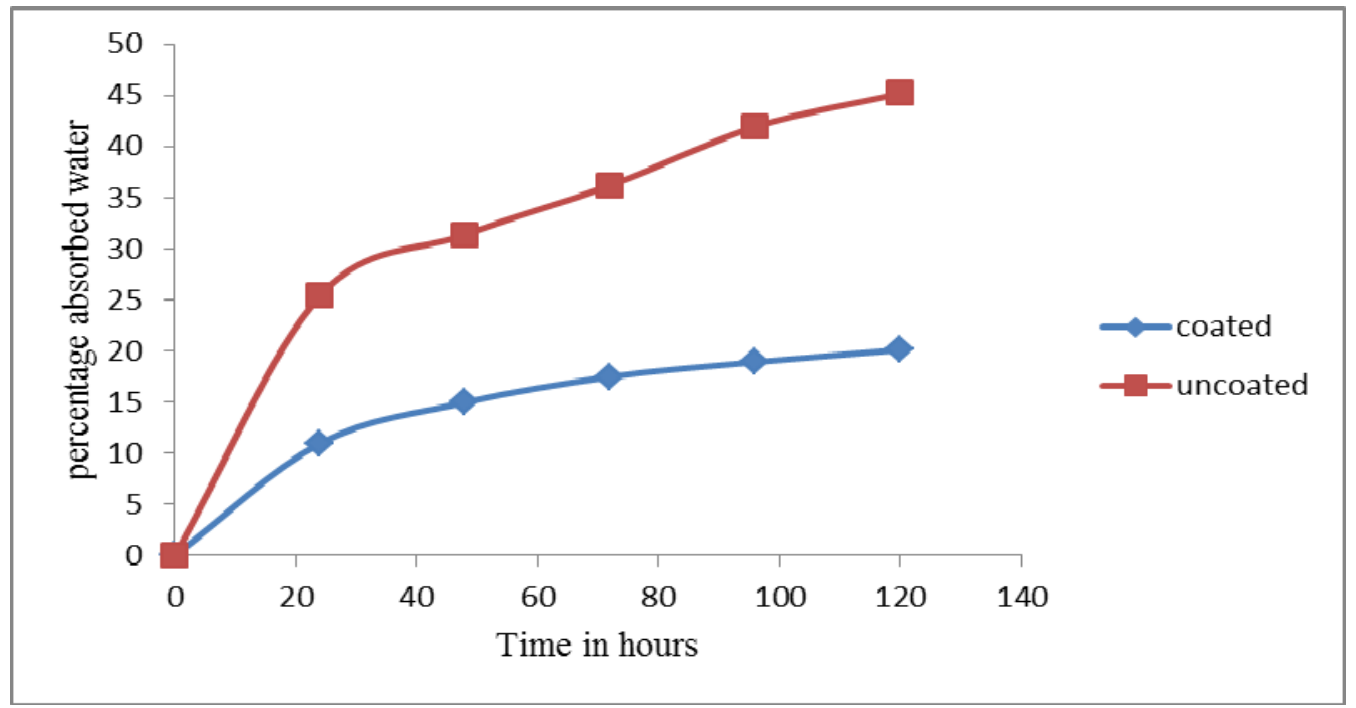

Fig.3. Water absorption vs time graph of bamboo specimens.

\section{Bond Between Concrete And Bamboo Surface}

The bond strength between bamboo and concrete is another important issue which has a great role to ensure ultimate strength of bamboo reinforced structure. Pull out test was conducted to predict the bond strength 
between bamboo and concrete. The bond between Bambusa balcooa and concrete is improved by providing a epoxy + sand coating on the bamboo surface. Epoxy reduces the water absorption which diminishes the swelling and shrinkage effect of bamboo reinforcement. Result shows that Epoxy and sand coating provides 2.24 times better bonding between bamboo and concrete.

\begin{tabular}{cc} 
& TABLE I Results of pull out test \\
\hline Types of Sample & Mean bond strength(MPa) \\
\hline Epoxy + sand coated & 4.26 \\
Uncoated & 1.9 \\
\hline
\end{tabular}

\section{E. Preparation of concrete beam Specimen}

In this experiment two point flexural tests were conducted on the beam samples with four different percentage of bamboo reinforcement (tensile). Details of reinforcement is shown in Table II and sectional views are shown in figure 4 and figure 5.Construction stages are also shown in figure 6.

TABLE II Beam reinforcement details

\begin{tabular}{llll}
\hline Reinforcement percentage & Cross section of bar & Number of tension bar & Number of hanger bar \\
\hline $0 \%$ & NA & NA & NA \\
$0.73 \%$ & $7 \mathrm{~mm} \times 10 \mathrm{~mm}$ & 2 & 2 \\
$1 \%$ & $9 \mathrm{~mm} \times 10 \mathrm{~mm}$ & 2 & 2 \\
$2 \%$ & $18 \mathrm{~mm} \times 10 \mathrm{~mm}$ & 2 & 2 \\
\hline
\end{tabular}

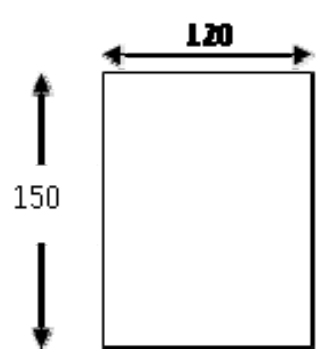

(a)

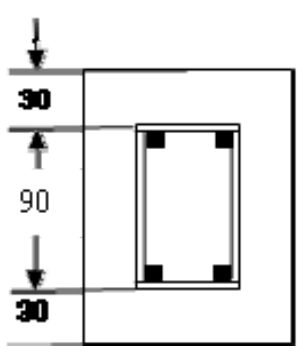

(b)

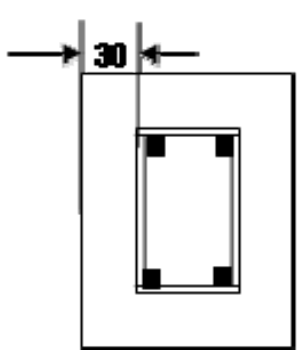

(c)

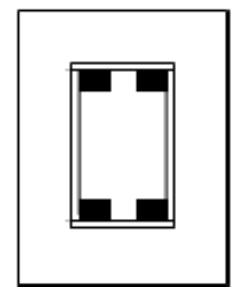

(d)

Fig.4. Cross section of (a) Plain concrete beam, (b) $0.73 \%$ bamboo reinforced beam, (c) $1 \%$ bamboo reinforced beam, (d) $2 \%$ bamboo reinforced beam, 


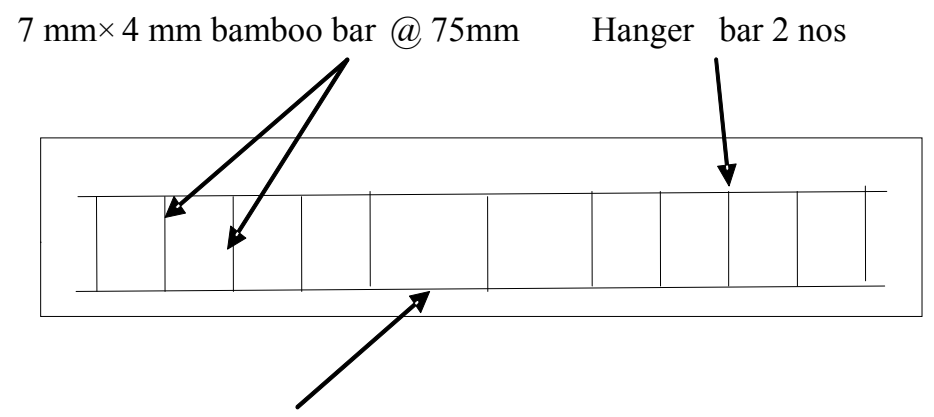

Main bar 2 nos

Fig.5. Reinforcement details of beam sample.

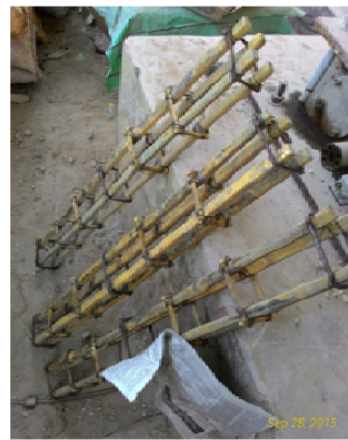

Binding

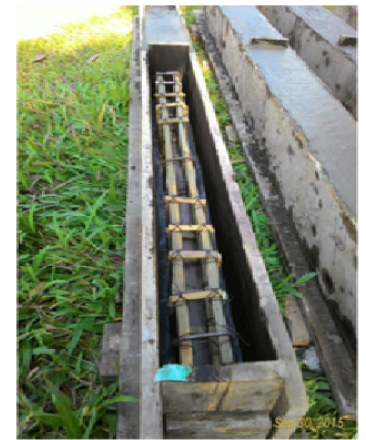

placing

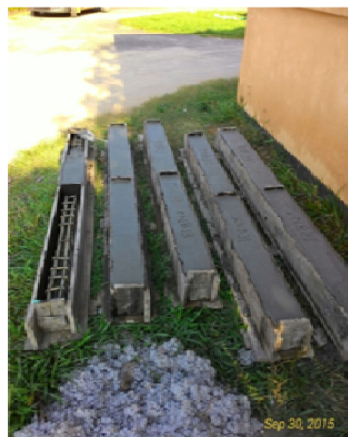

Casting

Fig. 6. Construction stages of bamboo reinforced beam.

\section{F. Flexural test on beam}

The casted beams were cured under water for 28 days. After curing they were taken into the structural engineering lab. The beam was placed on two supports as shown in figure 7. The supports were placed at $40 \mathrm{~mm}$ distances from the two edges. The third point loading bridge was placed on the beam. And it was centred perfectly. A $100 \mathrm{kN}$ capacity hydraulic loading machine was placed on the centre of the bridge. A mechanical dial gauge of least count $1 \mathrm{kN}$ was used to measure the load. Another dial gauge was attached at the middle span of the beam to measure the displacement of the middle span of the beam. The loading was given at a constant rate.

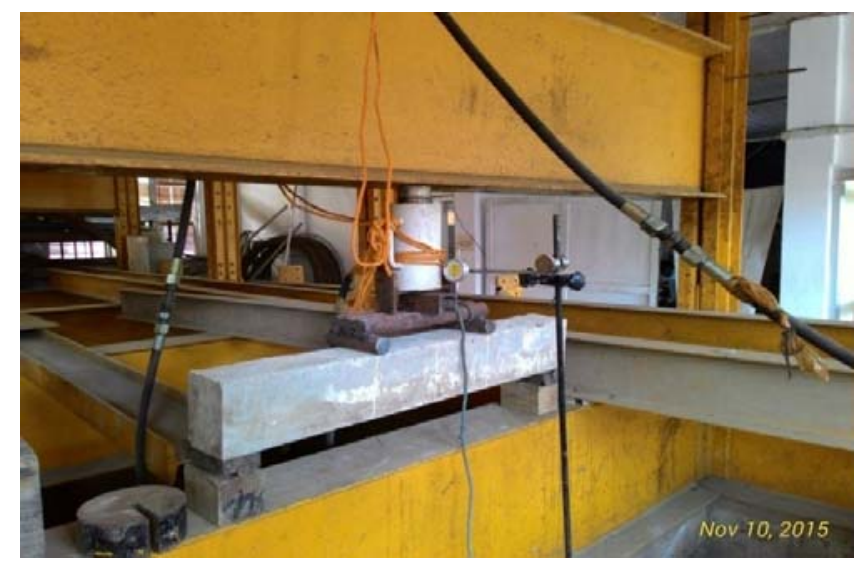

Fig. 7. The test setup for flexural test of beam samples 


\section{RESULTS AND DISCUSSION}

In two point loading test the plain concrete beam carried $6.83 \mathrm{kN}$ load. The failure was sudden and brittle. And the middle span displacement was $1.2 \mathrm{~mm}$. The failure pattern of the bamboo reinforced beam is shown in figure 8 . The load displacement curve of different reinforcement percentage concrete beam is shown in the figure 9. Use of bamboo reinforcement increases the ultimate load as well as deflection capacity of the beam samples. The maximum load carrying capacity of bamboo reinforced concrete beam increased from $23 \mathrm{kN}$ to $33.33 \mathrm{kN}$ when reinforcement percentage was increased from 0.73 to $2 \%$. The load displacement curve is similar for every bamboo reinforced beam upto $12 \mathrm{kN}$ load. Beyond this value the curve is stiffer with more percentage of tensile reinforcement. Figure 10 shows the variation of Ultimate load carrying capacity with percentage of bamboo reinforcement. Figure 11 shows the crack pattern of beam samples. In the present study the maximum load carrying capacity of $2 \%$ bamboo reinforced beam was found to be 4.88 times that of corresponding plain concrete beam. In the year 1995 Ghavami found the same 4 times with $3.33 \%$ of bamboo reinforcement. Shiddhpura et al (2013) found this ratio to be 3.45 for bamboo reinforced beam with Araldide coated 2 main and 2 hanger bars bamboo bars of $10 \mathrm{~mm}$ width.

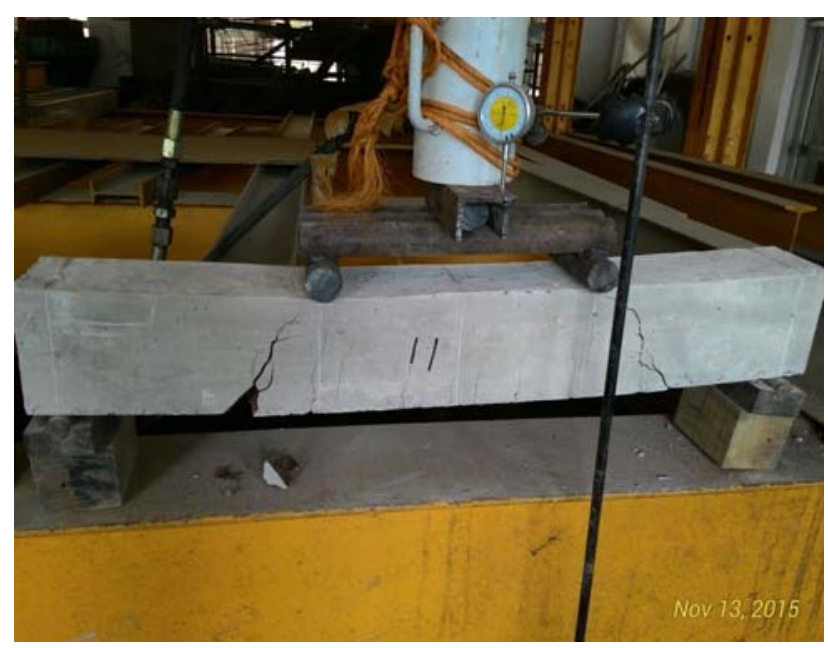

Fig.8. Failure of $0.73 \%$ BRC Beam

TABLE III Results of two point loading tests of beam samples with different reinforcement percentage

\begin{tabular}{cccc}
\hline $\begin{array}{c}\text { Reinforcement } \\
\text { percentage }\end{array}$ & $\begin{array}{c}\text { First visible crack } \\
\text { at load (kN) }\end{array}$ & $\begin{array}{c}\text { Displacement } \\
\text { at maximum load } \\
\mathbf{( m m})\end{array}$ & $\begin{array}{c}\text { Average maximum } \\
\text { load } \\
\mathbf{( k N )}\end{array}$ \\
\hline $0 \%$ & NA & 1.2 & 6.83 \\
$0.73 \%$ & 13.33 & 8.8 & 24.16 \\
$1 \%$ & 15.33 & 8.3 & 30.33 \\
$2 \%$ & 19 & 6.4 & 33.33 \\
\hline
\end{tabular}




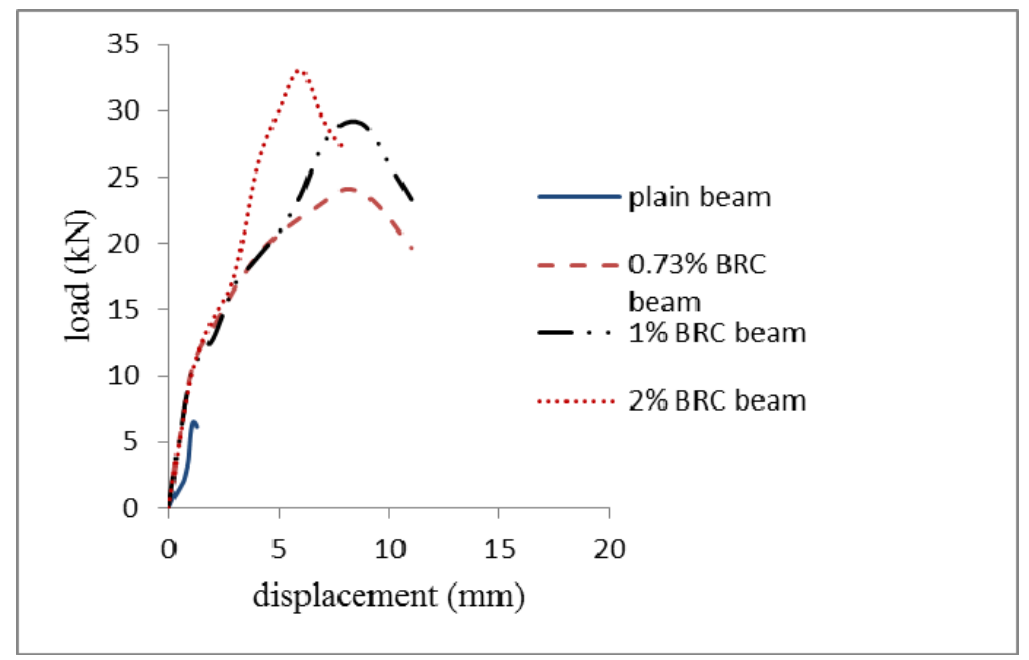

Fig.9. Comparison of Load-displacement curve of different types of beam

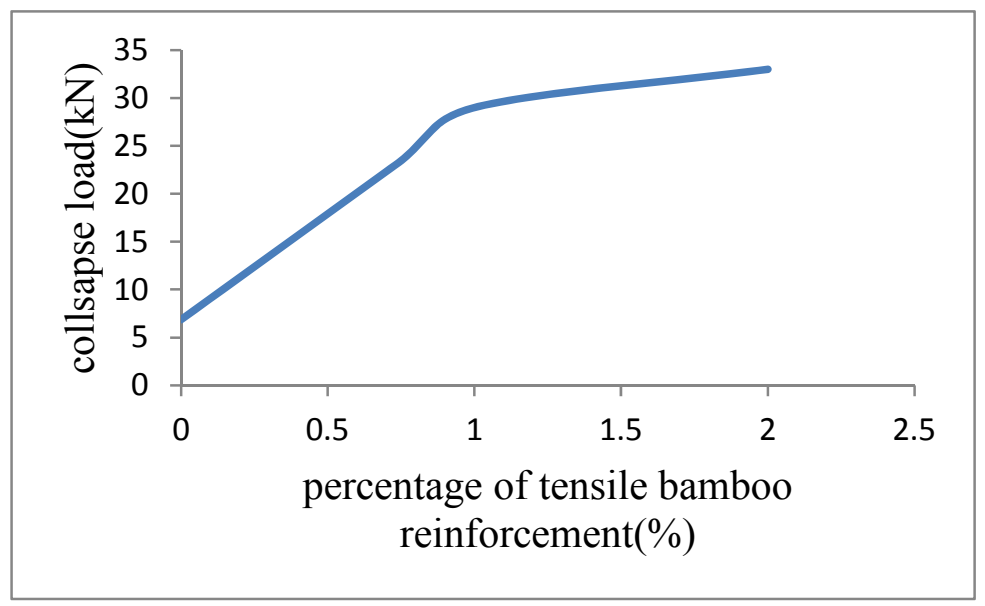

Fig.10. Variation of collapse load with bamboo reinforcement percentage

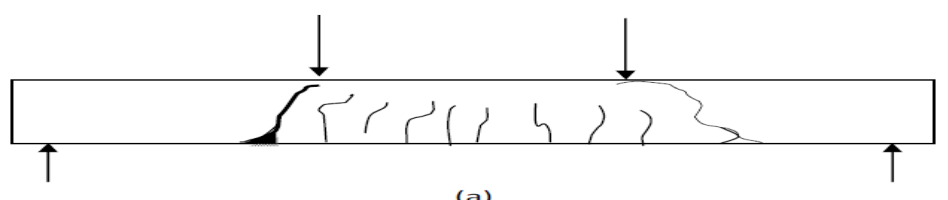

(a)
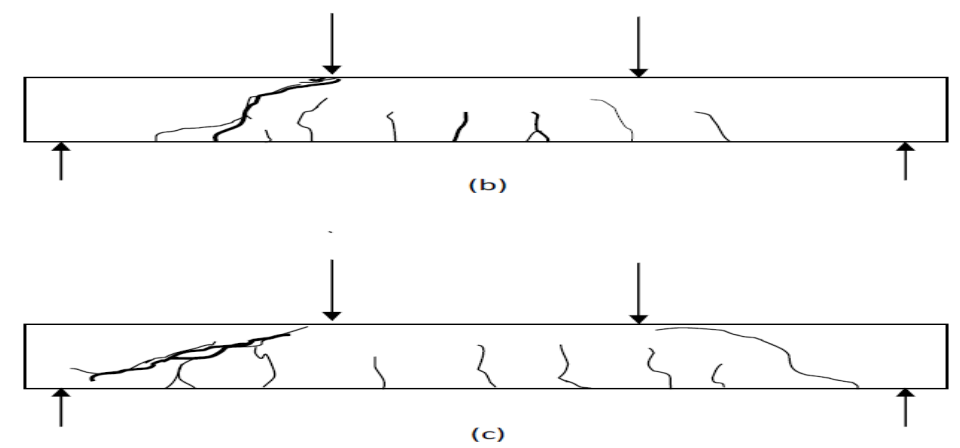

Fig.11. (a) Crack pattern of $0.73 \%$ reinforced beam, (b) Crack pattern of $1 \%$ reinforced beam, (c) Crack pattern of $2 \%$ reinforced beam 


\section{CONCLUSION}

In the above experimental study an attempt has been made to check the technical feasibility of utilizing Bambusa Balcooa as a reinforcing material in brick aggregate concrete structure. Different tests were conducted to evaluate different properties related to bamboo reinforced beam. Based on the results of those tests a brief conclusion is presented here.

- Bambusa Balcooa possess good tensile strength as well as ductility. The tensile strength of bamboo is greater than the yield strength of mild steel. This species of bamboo yields at 0.0042 strain with more than $62 \%$ of ultimate strength.

- Epoxy reduces the water absorption of bamboo up to great extent. Bond strength between epoxy coated bamboo and concrete found to be 2.24 times than uncoated samples

- Maximum load carrying capacity of Bamboo reinforced brick aggregate concrete beam was noticed to be 4.88 times that of plain concrete beam with $2 \%$ bamboo reinforcement.

- The strength of bamboo reinforced beam increases with the increment of bamboo reinforcement in the range of 0 to $2 \%$.

\section{REFERENCES}

[1] Ghavami, K., "Ultimate Load Behaviour of Bamboo-Reinforced Lightweight Concrete Beams", Cement \& Concrete Composites 17 (1995) 281-288, 10 May 1995.

[2] Ghavami, K., "Bamboo as reinforcement in structural concrete elements", Cement \& Concrete Composites 27 (2005) 637-649, 4 June 2004

[3] Ghavami, K. ,"Structural Concrete Reinforced with Bamboo", Asian Journal of Civil Engineering (Building and Housing ), vol.2,2001

[4] Khan, I.K., " Bamboo Sticks as a Substitute of Steel Reinforcement in Slab” International Journal of Engineering and Management Research Volume-4, Issue-2, April-2014, ISSN No.: 2250-075, April 2014.

[5] Kaware, A. Awari, U.R. Wakchaure, M.R., "Analysis Of Bamboo Reinforced Concrete Column”, International Journal of Innovative Research in Science, Engineering and Technology, Vol. 2, Issue 6, June 2013.

[6] Lugt, P. Dobbelsteen, A.A.J.F. Janssen, J.J.A.,“An environmental, economic and practical assessment of bamboo as a building material for supporting structures”, Construction and Building Materials 20 (2006) 648-656, 18 February 2005

[7] Mark, A.A. Russell, A.O.,"A comparative study of Bamboo reinforced concrete beams using different stirrup materials for rural construction", International Journal Of Civil And Structural Engineering Volume 2, No 1, 2011, ISSN 0976 - 43991 , November 2011

[8] Naznin, F. Chetia, N.,"A Study on Bamboo Reinforced Concrete Beams”, International Journal of Science and Applied Information Technology (IJSAIT), Vol. 4 , No.3, Pages : 49 - 53, July 2015

[9] Sabnani, C. Latkar, M. Sharma, U.,"Can Bamboo Replace Steel as Reinforcement in Concrete, for the key Structural Elements in a Low Cost House, Designed for the Urban Poor?”, International Journal of Chemical, Environmental \& Biological Sciences (IJCEBS) Volume 1, Issue 2 (2013) ISSN 2320 -4087, 2013.

[10] Sethia, A. Baradiya, V., "Experimental Investigation On Behavior Of Bamboo Reinforced Concrete Member", International Journal of Research in Engineering and Technology eISSN: 2319-1163, July 2015

[11] Siddhpura, N.B. Shaha, D.B. Kapadia, J.V. Agrawala, C.S. Sevalia, J.K.,"Experimental Study on Flexural Element using Bamboo as Reinforcement”, International Journal of Current Engineering and Technology ISSN 2277 - 4106, June 2013 